completed, if nothing untoward intervenes, by May next. It was intended that the School should open there for the session 1940-41. In the recently issued annual report for the session 1938-39, the first of Lord Harlech's chairmanship of the Governing Body, it is recorded that, in response to an appeal which he, as MIr. Ormsby-Gore, when Secretary of State for the Colonies, had put forward, the Colonial Office las promised a sum of $£ 4,380$ per annum in sub. vention of the work of the School, while a grant of $£ 2,500$ has been made by the University Court for the remainder of the quinquennium for the establish. ment of fivo posts-ono lectureship in Japanese, one in Turkish, and three in Arabic dialects, while a later grant of $£ 500$ for a period of not less than three years was made for a lecturership in Sinhalese. The number of students, though representing a slight decrease, was still more than four hundred. While the numbers from Great Britain and the Empire showed a decrease, there was a considerable addition to those from Germany and the United States.

In the course of the report, reference is made to the valuable assistance towards African studies given by grants from the Rockefeller Foundation which during tho last seven years have amounted in sums allocated to public bodies and to individuals to a total of $£ 18,000$. It will be remembered that it was through the assistance of a grant from this source, spread over fivo years, that the International Institute of African-Languages and Cultures was enabled to plan and carry out its valuable scheme of organized African research in the field, of which the benefit is now becoming apparent not only in the monographs in course of publication but also in the projects for further research which directly or indirectly have sprung from that scheme.

\section{Dr. Jean Paul Marat}

IN a recent paper (Hippocrate, 7, 379; 1939) Dr. Henri Candiani protests against the unjust and cruel treatment which Marat has received not only from scurrilous pamphleteers but also from reputable historians such as Michelet, Taine and Carlyle. While not attempting to refute all the legends and calumnies concerning the "Friend of the People", Dr. Candiani confines himself to the scientific and medical aspects of his hero. So far from being a charlatan or merely a horse-leech, as Carlyle called him, he was a properly qualified medical man of St. Andrews who, during his residence in London, had a good practice in Soho when that district was a fashionable quarter. His "Essay on Man" (1775), more than half of which is devoted to anatomy, is a philosophical and psycho. logical work, in which he has been recognized as the precursor of Cabanis, Broussais and Gall. In his "Essay on Gleets", published the same year, he criticized certain errors of treatment curront at the time, including the use of hard and irritating bougies, for which he substituted softer instruments. In 1776 he made an important contribution to ophthalmology in his "Enquiry into a Singular Disease of the Eyes", in which, as Prof. Truc of Montpellier has shown, he gave a description of astigmatism which preceded the classical account of Thomas Young by more than twenty years. But it was as a pioneor in electro. therapy, on which he wrote in 1782 and 1783, that Marat chiefly deserves mention in the history of medicine. According to Dr. W. G. Turrell of Oxford, his work on this subject was on far more scientific lines than the writings of any of his predecessors or even than the publications of many of his successors. In conclusion, Dr. Candiani describes Marat as a conscientious experimenter, resolutely hostile to absurd theories or hasty generalizations.

\section{Food of Game Ducks}

VARIOUS causes have contributed to reduce, to a serious extent in some cases, the numbers of gamo ducks in the United States and Canada, and tho interest of the public and the self-interest of the multitude of shooters alike demand that measures should be taken for the encouragement and multiplica. tion of the duck population. The U.S. Department of Agriculture has responded to the demand by the publication of a pamphlet (Washington, D.C.: Tech. Bull. No. $634 ; 1939$ ) of 156 pages and 153 plates, with the aim of spreading dependable information on which programmes for the improvement of breeding and feeding grounds may bo based. To minimize waste of funds and loss of effort through the introduction of unsuitable foods, it is essential that the important plant and animal foods of the various species be known and that consideration be given to the range of particular species and environmental and other limiting factors. By making use of data accumulated through many years by the Biological Survey, the authors, A. C. Martin and F. M. Uhler, have presented a thorough-going treatise which from three aspects gives a lead to duck conservation and propagation. The first section presents a census of foods, based upon analyses of nearly 8,000 stomachs or gullets of eighteen species of game ducks, and indicates the regions in the United States where each food is preferred. The second part, by means of photographs and concise descriptions, is designed to facilitate recognition of these foods; and the third part contains practical suggestions on the propagation of the food of waterfowl and the development of feeding grounds.

\section{Fauna of the Marquesas Islands}

Isolated in the central Pacific Ocean, farther from the continents than any others, with one exception, themselves the relics of volcanoes perhaps of Pliocene age, the Marquesas Islands afford a perfect setting for the study of an oceanic island fauna. The study has been carried out with thoroughness by A. M. Adamson, who spent fifteen months collecting on the Islands and has made a survey of the literature bearing on the problem (Bull. Bernice P. Bishop Museum, Honolulu, 159,.93; 1939). Marquesan animals are related to those of the island groups lying to the west and south-west, Samoa, Society, Cook, etc., but they show little affinity to the fauna of Hawaii. The 